\title{
"Medicos Self-Medicate More"- A Comparative Study among Medical and Non-Medical Undergraduate Students
}

\author{
Dr. Amit Kumar Ghosh ${ }^{1 *}$, Aayush Bhadani ${ }^{2}$, Sayantan Debnath ${ }^{3}$ \\ ${ }^{1}$ Associate Professor, Pharmacology R.G.Kar Medical College, Kolkata, India \\ ${ }^{2} 2$ nd Year Mbbs Student, R.G.Kar Medical College, Kolkata, India \\ ${ }^{3}$ 2nd Year Post Graduate Student, Pharmacology, R.G.Kar Medical College, Kolkata, India
}

DOI: $10.36348 /$ sjmps.2019.v05i12.010

| Received: 08.12.2019 | Accepted: 19.12.2019 | Published: 25.12.2019

*Corresponding author: Amit Kumar Ghosh

\section{Abstract}

Self-medication is taking any therapeutic drug without doctor's prescription. This practice is a potentially hazardous public health problem. It is commonly practiced in India as it provides a low-cost alternative treatment. Our objective was to find out the correlation between self-medication in medical vs. nonmedical students. It was a cross-sectional study, carried out using a pre-validated, semi-structured, self-administered questionnaire, a medical and a anon-medical undergraduate group consisting of 100 students each. Established statistical methods were used for analysis. It was found that $68 \%$ of the medical students self-medicated compared to $48 \%$ of the non-medical counterparts, higher in females. Awareness about side-effects, disadvantages, need of correct dosage and importance of course completion was more among the medicos. Upon analyzing the data from medical and non-medical groups we observed that most of them cited mild illness ( $82 \%$ and $69 \%$ respectively) as a reason for self-medication. Common-cold was the most common complaint and antipyretics (78\% and $77 \%$ respectively) were the most commonly taken drug. Drug stores (78\%) were the primary sources of obtaining medicines, while previous medication experience from the same illness was the main source of knowledge of dosage. More than 50\% participants supported the use of self-medication in the treatment of common illnesses. Conclusion is that main reason of self-medication among medical students can be a better knowledge and understanding about the various aspects of medication, reflecting the influence of medical training and studies. However, an incomplete knowledge and understanding makes self-medication a potentially harmful practice.

Keywords: Medical and non-medical students, self-medication, medicines, antipyretics, prescriptions, awareness.

Copyright @ 2019: This is an open-access article distributed under the terms of the Creative Commons Attribution license which permits unrestricted use, distribution, and reproduction in any medium for non-commercial use (NonCommercial, or CC-BY-NC) provided the original author and source are credited.

\section{INTRODUCTION}

William Osler once commented, "The desire to take medicine is perhaps the greatest feature which distinguishes man from animals". This desire is perhaps the key factor for the self-medication which is defined as the selection and use of medicines by individuals to treat self-recognized illnesses or symptoms. The International Pharmaceutical Federation defines selfmedication as the use of non-prescription medicines by people on their own initiative.

These medicines for self medication often called 'over the counter drug' are sold directly to a consumer without a prescription from a healthcare professional. Self-medication is one element of selfcare. But, unlike other aspects of self-care, selfmedication involves the use of drugs and drugs have the potential to do well as well as do harm [1].
It is important for the public to realize all drugs have side effects. It does not matter if they are prescription, over-the-counter, herbals or nutritional supplements. If they have active ingredients, they have side effects and can interfere with normal body functions [9]. The practice of self-medication must be based on authentic medical information otherwise irrational use of drugs can cause wastage of resources, increased resistance to pathogens, and can lead to serious health hazards such as adverse drug reaction and prolonged morbidity [12].

Now a days, the term 'responsible' selfmedication is often used, meaning that the use of appropriate drugs, such as over the counter (OTC) drugs, is limited only to the situations for which they are necessary [13]. Responsible self-medication requires a certain level of knowledge by those who practice it [14]. The World Health Organization (WHO) 
has appropriately pointed out that responsible selfmedication can help to prevent and treat diseases that do not require medical consultation and provides a cheaper alternative for treating common illnesses.

In developing countries like India, selfmedication is a common practice as it provides a lowcost alternative for people who cannot afford the high cost of clinical service and also as many drugs are dispensed over the counter without prescription from a registered medical practitioner. Also, the Economic, political, and cultural factors have stimulated a constant increase in self-medication worldwide, turning this practice into a major public health problem [8].

Self-medication can result in harm to the student; the long-term outcome may be a qualified healthcare professional who then self-medicates with more dangerous drugs; or one who prescribes for family members; or one who ignores or encourages irresponsible use of medications among patients [15]. Also, doctors make the worst patients because they resort to self-medication as they know all about drugs.

The youth are highly influenced by the media and the internet which promotes self-medication behavior [16]. The increased advertising of pharmaceuticals poses a larger threat of self-medication to the younger population in general. This raises concerns of incorrect self-diagnosis, drug interaction, and use of drugs other than for the original indication [17]. In the state of West Bengal, the percentage of medical students comes down to mere $2.75 \%$. By conducting a cross-sectional study we will be able to get a brief analysis on the self-medication awareness and practices of the undergraduate students in west Bengal and further promote rational use of medicines. This study would also bridge up the gap which may exist among the undergraduates belonging to two different disciplines by conducting awareness campaigns and enforcing medication dispensing laws which may be needed for self-medication.

\section{OBJECTIVES}

\section{Our Primary Objectives was}

- To evaluate the knowledge and awareness of Undergraduate students regarding Self-Medication.

- To check whether the stream of undergraduate study (medical or non-medical) co-relates with the self-medication.

- To find out the pattern of self-medication and corelate it with the socio-demographic factors.

\section{MATERIAL AND METHODS}

Type of study: A cross sectional study was carried out using a pretested, pre-validated, semistructured, self-administered questionnaire.
Participants: Pre Clinical Medical and NonMedical Undergraduate students belonging to different colleges in West Bengal. Medical students included Pre-Clinical Students (1st and 2nd year MBBS students). Non-Medical Students included students from all other disciplines.

Study Duration: A period of 2 months (2nd July 2017 to 2nd September 2017)

Sample Size: A pilot study was conducted on 10 Pre-Clinical Medical students and 10 Non Medical students. A close ended question- "Have you taken any Self-Medication in the last 6 months/during the last episode of illness?" was asked to them and the answers were noted down. By substituting the values we get $\mathrm{N}=$ 196 Therefore, the Sample size for this study was taken as 100 Medical and 100 Non-Medical Undergraduate Students.

Sample Design: Simple random sampling technique was employed in this cross-sectional study.

Study Tool: A pretested, semi-structured, selfadministered questionnaire was used. This questionnaire had 3 parts.

Part A: Self-Medication Behavior. (Only participants who had self-medicated in the last 6 months/during last 6 months were asked to fill this part, except Question No.1 (Have you taken any selfmedication in the last 6 months/during the last episode of illness?)

\section{Part B: Knowledge}

Part C: Socio-Demographic Details Part B and Part $\mathrm{C}$ were filled by all the participants. The questions were of following types: i. Questions with multioptions. (In few questions only one option was allowed to be marked, in others, multi-options could be marked). ii. Close ended questions ending with Yes, No, Don't know etc. iii. Open ended questions (e.g., what do you understand self-medication?)

Ethical Committee Approval: Preceding the study, ethical committee approval was taken from the Institutional Ethics Committee of R.G. Kar Medical College; Kolkata (dated 23rd June, 2017).

Data management and statistical analysis: The data was managed and analyzed by Statistical Package for the Social Sciences (SPSS) for Windows Version 64 bit (SPSS Inc; Chicago, IL, USA) and Microsoft Excel.

Procedure:- The participants were informed about the nature and purpose of study and necessary informed consent was obtained. They were informed that their Identity would remain confidential and were given proper instructions to fill up the questionnaire. 
Total 236 responses were obtained out of which some were rejected based on the response to the question, "What do you understand by self-medication? Comment in a few lines." Any therapeutic drug taken without a doctor's prescription was considered as selfmedication. Responses of the participants, who didn't know- what is self-medication, were excluded. Also, few responses were discarded randomly to make the sample size 100 each. The data obtained was double entered and analyzed and expressed in terms of figures, percentages, Bar graphs, Pie-charts, and tables and were compared by using Chi-Square tests and other statistical tools.

\section{RESULTS}

$68 \%$ of the medical and $48 \%$ of the nonmedical students selected self-medicated in the last 6 months. Among the medical students, $18 \%$ of the students self-medicated once, $28 \%$ self-medicated twice, $10 \%$ self-medicated thrice and $44 \%$ selfmedicated more than three times compared to the nonmedical students, among whom, $17 \%$ of the students self-medicated once, 39\% self-medicated twice, $4 \%$ self-medicated thrice and $40 \%$ selfmedicated more than three times in last 6 months.

Among the medical students, the reason for self-medication was mainly due to minor ailment (82\%), followed by quick relief(37\%), convenience( $32 \%)$, urgency $(26 \%)$, cost saving(10\%) and lack of trust on the prescribing practitioner(1\%). While only $4 \%$ resorted to self-medication because of other reasons. A similar trend was seen among the nonmedicos, as the reason for self-medication was mainly due to minor ailment $(69 \%)$, followed by quick relief (46\%), urgency (27\%), convenience(19\%), cost saving $(6 \%)$. While only $2 \%$ took self-medication because of other reasons.

Antipyretics (Paracetamol) are the most commonly self-medicated drug with a prevalence of $78 \%$ and $77 \%$ among Medical and Non-Medical Students respectively. 40\% Medicos and $21 \%$ NonMedicos had Self-Medicated with Gastrointestinal Remedies (e.g. Antacids, Anti-Diarrheal, and Laxatives etc). Antibiotics (E.g. Penicillin, Fluoroquinolones, Macrolides, Cephalosporin) were commonly selfadministered, 29\% among the Medicos and 17\% among the Non-medicos. Other Self-Administered drugs are Anti-allergic drugs (e.g. Cetrizine, Montelukast etc) [24\% and 29\%], NSAIDs (e.g. Ibuprofen) [13\% and $17 \%$ ], Cough and Cold Remedies (e.g. Cough syrups) [9\% and $13 \%$ ], Topical Remedies (e.g. Soframycin, Burnol, Nasal Decongestants) [9\% and 15\%] and AntiEmetic drugs (e.g. Domeperidone etc) [7\% and 2\%] for [Medical and Non-Medical Students] respectively.

A similar trend was seen among the medical and non-medical students regarding source of obtaining medicine was self-medication and when combined together, the source of the medications are $78 \%$ from pharmacies, $30 \%$ from the friends and families, $13 \%$ from leftover from the previous prescriptions, mere $2 \%$ from online shopping while $3 \%$ from other sources. None sought the help of a Baidya for self-medication.

Among the medical students and non-medical students, the source of information of the dosage of medicine was from previous experience $(66 \%$ \& 69\%), family members, friends $(29 \% \& 25 \%)$, package insert $(22 \% \& 10 \%)$, pharmacist (22\% \& $29 \%)$, Internet (9\% \& $8 \%)$, newspapers, magazines, books, TV programs $(3 \%$ $\& 2 \%)$ respectively and by guessing the dosage $(6 \%$ each)

Among the 68 medical and the 48 non-medical students, $86 \%$ medical students were aware of the probable side-effects of the medicine self-administered compares to only $65 \%$ non-medical students who were aware regarding this aspect. $82 \%$ Medical students and $71 \%$ non-medical students were concerned about the quality of medicine they took, while only $1 \%$ and $3 \%$ respectively were unaware of the disadvantages of selfmedication.

$54 \%$ Medicos as well as Non-Medicos stopped taking the medicine only after the symptoms disappeared. Whereas, only 37\% Medicos and 23\% Non-Medicos discontinued it after completion of the course. $9 \%$ and $13 \%$ respectively stopped taking medicines after few days regardless of the symptoms. While, 22\% Medicos and 17\% Non-Medicos discontinued it a few days after the recovery. $10 \%$ NonMedicos consulted a doctor/pharmacist compared to $1 \%$ medicos. $4 \%$ Non-Medicos stopped after medicines ran out. 2\% Non-Medicos also had other reasons.

In case of Medical Students, in $35 \%$ of the cases the symptoms subsided after self-medication whereas in only $12 \%$ Non-Medical students such was the case.

In cases, where symptoms did not subside$53 \%$ Medicos and $77 \%$ Non-Medicos consulted a doctor, 6\% Medical Students stopped taking the medicine, $3 \%$ switched to another medicine and $1 \%$ did nothing. 2\% Non-Medical Students Switched to another medicine, $4 \%$ consulted family members/friends and $4 \%$ did nothing. None of them went to a Pharmacist. $1 \%$ Medicos had other reasons.

7\% Medical students think Self-Medication to be a good practice compared to $16 \%$ Non-Medical Students. $60 \%$ of the Medical as well as the NonMedical students considers it to be an acceptable practice, whereas only 33\% (Medicos) and $24 \%$ ( NonMedicos) considers it as not an acceptable practice. 
Table-1: Shows opinion of self-medications

\begin{tabular}{|l|l|l|l|}
\hline Self-medication for self -health care? & Medical & Non-Medical & Grand Total \\
\hline A. Good practice & $4(6 \%)$ & $7(15 \%)$ & $11(9 \%)$ \\
\hline B. Acceptable practice & $44(65 \%)$ & $38(79 \%)$ & $82(71 \%)$ \\
\hline C. Not acceptable practice & $20(29 \%)$ & $3(6 \%)$ & $23(20 \%)$ \\
\hline Self-Medicated & 68 & 48 & 116 \\
\hline A. Good practice & $3(9 \%)$ & $9(17 \%)$ & $12(14 \%)$ \\
\hline B. Acceptable practice & $16(50 \%)$ & $22(42 \%)$ & $38(45 \%)$ \\
\hline C. Not acceptable practice & $13(41 \%)$ & $21(40 \%)$ & $34(40 \%)$ \\
\hline Not Self-Medicated & 32 & 52 & 84 \\
\hline TOTAL & 100 & 100 & 200 \\
\hline
\end{tabular}

$54 \%$ Medicos and 56\% Non-Medicos supported the use of self-Medication. $21 \%$ and $15 \%$ respectively showed no support. $25 \%$ and $29 \%$ respectively were not sure.

Table-2: Supporters and non-supporters of self medication

\begin{tabular}{|l|l|l|l|}
\hline $\begin{array}{l}\text { Do you support the use of self-medication in the treatment } \\
\text { of common diseases? }\end{array}$ & Medical & $\begin{array}{l}\text { Non- } \\
\text { Medical }\end{array}$ & $\begin{array}{l}\text { Grand } \\
\text { Total }\end{array}$ \\
\hline A. Yes, I support & $42(62 \%)$ & $35(73 \%)$ & $77(66 \%)$ \\
\hline B. No, I don't & $9(13 \%)$ & $2(4 \%)$ & $11(9 \%)$ \\
\hline C. I am not sure & $17(25 \%)$ & $11(23 \%)$ & $28(24 \%)$ \\
\hline Self-Medicated & 68 & 48 & 116 \\
\hline A. Yes, I support & $12(38 \%)$ & $(40 \%)$ & $33(39 \%)$ \\
\hline B. No, I don't & $12(38 \%)$ & $13(25 \%)$ & $25(30 \%)$ \\
\hline C. I am not sure & $8(25 \%)$ & $18(35 \%)$ & $26(31 \%)$ \\
\hline Not Self-Medicated & 32 & 52 & 84 \\
\hline TOTAL & 100 & 100 & 200 \\
\hline
\end{tabular}

83\% Medical Students considered adverse drug reactions as a major disadvantage of selfmedication compared to $47 \%$ Non-Medical students who felt so. Also, $84 \%$ of the Medicos cited that lack of knowledge regarding the side-effects, dosage, and course of treatment can be harmful. This was cited by $63 \%$ Non-Medicos only. $56 \%$ the Medical Students feel the disease can be aggravated by taking self-medication compared to 33\% Non-Medical Students. 71\% Medical Students and $65 \%$ cited that wrong medication may be taken. 3\% Non-Medicos feel that there are no disadvantages of Self-Medication whereas, only $1 \%$ Medicos think so. 2\% Medicos and 1\% Non-Medicos cited other reasons.

\section{DISCUSSIONS}

Several studies have reported the practice of self-medication among the Medical and Non-Medical students. In our study, the prevalence of self-medication was comparable in both groups i.e. among the Medical and Non-Medical undergraduate students.

$68 \%$ of the Medical students self -medicated compared to $48 \%$ of the Non-Medical students. There are many reasons for this increased likelihood of selfmedication among Medical students. These students have easy access to information from drug indices, literature, and other Medical students to self-diagnose and self-medicate [18]. Among the medical students in India, the prevalence varies from $57.06 \%$ in West
Bengal [7], 79.1\% in Mangalore, Coastal South India $80.1 \%$ in Tamil Nadu[19] and $87 \%$ in Uttar Pradesh [20], 88.18\%(In Karnataka)[8] to $92 \%$ in South India[6]. Worldwide, the data obtained were $25.4 \%$ and $43.2 \%$ in Ethiopia [21, 22] $56.9 \%$ in Nigeria [23], $79.9 \%$ in Serbia and $80.9 \%$ in Malaysia [24] to as high as $97.8 \%$ in Kuwait [10]. Similar data were obtained among the non-medicos in a study conducted in Karachi, Pakistan, where $50.1 \%$ of the Non-Medical university students had self-medicated in the last 6 months [3] Also, in a study conducted in Egypt among university students, the prevalence of self-medication was Medicos (72.4\%) and Non-Medicos (52.6\%) similar to the results obtained in this study[5]. But, it is very difficult to compare the prevalence of different studies with present study due to different demographic characteristics and different socioeconomic status [4].

In our study, 2nd year Medical students (70\%) were seen to self-medicate more than the 1 st year Medical students $(65 \%)$ as they are exposed to knowledge about drugs and disease. This is similar to the results obtained in previous studies, conducted at a tertiary Medical College in West Bengal. (2nd Year $52.17 \%$ \& 1st Year- 41.67\%) [7] Conducted in Karnataka. Conducted in Maharashtra [11]. But contra indicatory to that obtained in another study [1].

The predominant age group in our study was 19-20 years comprising $71 \%$ of the participants $41 \%$ of the participants were female and $59 \%$ of them were 
male. Females were seen to self-medicate more $(73 \%$ females compared to $65 \%$ males in Medicos) and (50\% females compared to $47 \%$ males among the NonMedicos). This trend was seen in a study conducted by James H hindu et al. [25] $44 \%$ females to $43 \%$ males and some other studies from India [7] and abroad [26]. Contrasting results were obtained in the study done by Badiger S et al. [6] (94\% males to $91 \%$ females) and in a study conducted in Pokhara, Nepal [2]. The reason can be frequent self-medication for menstruation regarding problems and an inherent tendency of increased self-medication as seen in other studies.

Participants with monthly allowance $\geq 3,001$ rupees made the maximum percentage, $36.2 \%$ among those who self-medicated. This may be due to the fact that more financial resources, helps them to have a better access towards the sources of medicines for selfmedication. In a study conducted in Libya, the rate of self-medication among higher classes was more as compared to lower classes [27].

Most of the participants had self-medicated more than 3 times in the past 6 months this gives an estimate about the prevalence of self-medication among the undergraduate students. In a study conducted in Karnataka, for a time frame of 6 months, maximum participants had Self-Medicated 2-3 times [8].

When asked for reasons, maximum people cited minor ailments (82\% Medicos and 62\% NonMedicos) as a reason for self-medication followed by quick relief, convenience, urgency and cost saving. Similar to those obtained in Karnataka [8]. These observations are similar to those reported by the WHO that Self-medication provides a cheaper and convenient alternative for treating common minor illnesses [28]. One participant had lack of trust in prescribing doctor and the other reasons cited were previous experience with same drug and illness.

Cough and cold was the most common complaint $(47 \%)$ for which participants Self-medicated which is similar to that obtained in a previous study in West Bengal [7] and Karnataka [8]. Fever was the second most common complaint. However, Fever was the most common indication for self-medication in a study conducted in Ethiopia [21]. This was followed by aches and pains, runny nose, sore throat and nasal congestion. As Bengal is a diarrhoea prone area, it was a common complaint for which participant selfmedicated [7]. Itching and constipation were cited as other reasons.

$78 \%$ Medical and $77 \%$ Non-Medical students confessed to have Self-administered Paracetamol - one of the most commonly taken over the counter drugs. Similar observations were made in a study from South India [6] and Ethiopia [21]. However, in studies from
Pakistan, and Egypt [5] analgesics was the most common group of drugs self-medicated. Antibiotics were used maximum by students in Karnataka [8]. Gastrointestinal remedies were taken by $40 \%$ Medicos and $21 \%$ Non- Medicos. The results are similar to other studies [6].

A major proportion $29 \%$ Medicos and $17 \%$ Non- Medicos confessed to have used antibiotics. Higher use of antibiotics among Medicos may be due to the fact, that they know more about the anti-microbial, its mechanism of action and proper use. But, its incorrect use can lead to antibiotics resistance, severe side effects and complications. Conflicting reports are available about the use of antimicrobials by SelfMedication. Less use of antimicrobials in senior Medical students has been reported by James $\mathrm{H}$ in 2008[18]. Another study showed low results because the governments in the countries to which the study respondents belonged have strict regulatory policies about the prescription and OTC sale of antimicrobials. Some studies have reported that a higher use of Medication is higher only in countries where these drugs are freely available OTC as observed in the present study as well as in other studies. Thus, it is once again observed that use of antimicrobials is always high where there is lack of implementation of proper regulatory control over the OTC sale of these drugs and the only measure that can be effective in tackling this problem would be enforcement of strict regulations and severe penalties for defaulters [1].

More Non- Medicos (8\%) have taken homeopathy medicines compared to Medicos (1\%). This can be due to the fact that Medical students are being trained in modern medicine. Similar observations were made in other studies from India [8].

Pharmacies were the main source of obtaining medicines for self-medication (78\%). This highlights the fact that the Pharmacist can play a key role in helping people to make informed choices about selfmedication and in providing and interpreting the information available and they need to be made aware of its disadvantages [10]. Friends and family, leftovers from previous prescription and previous experience were also some sources. E-shopping and E-pharmacies still do not play a major role. One of the Medical students obtained medicines from the samples his parents, being doctors, received from companies and a major percentage of Medical students have their parents in Medical profession.

Previous experience with same medicine was also cited as a source of information of dosage of medicines. Other sources include- pharmacist, friends and family members. $6 \%$ of them had guessed the dosage which might be detrimental. Different results were obtained in a study conducted in Maharashtra, 
where reading materials e.g., package inserts were the main source [11] and in a study conducted in Kuwait, where pharmacies were the main source [10].

$50 \%$ of the Medicos changed the dosage deliberately compared to $34 \%$ of the Non- Medicos, in contrast to the fact that Medical students are made more aware about the need of correct dosage and complete duration of treatment. Those who changed the dosage cited improving conditions as the major reason. Also a major proportion of Non- Medicos felt that was insufficient for complete treatment.

Majority of the Medicos and Non- Medicos stopped taking the medicines after symptom disappeared, but only $37 \%$ of the Medicos did it at the completion of the course. This percentage is even low in case of Non- Medicos. This again shows the less awareness about completion of a course among NonMedicos and thus highlights the gap which exists among the undergraduates belonging to the two different disciplines.

The symptoms subsided in $35 \%$ of the Medical participants who self-medicated compared to only $12 \%$ in case of Non- Medicos. This difference can be due to better knowledge of Medicos about the quality of medicine taken, the correct dosage, the side effects and importance of the completion of the course. When the symptoms persisted most of them consulted a doctor. Few Medicos also stopped taking the medicines, while few switched to another medicine. No one consulted a pharmacist this time.

It was also seen that few of the participants who did self-medication suffered from chronic illnesses in which asthma was one of the main diseases and some participants had self- medicated for asthma (e.g., levosalbutamol) also some suffering from hypertension took medicines contraindicated in it (e.g., xylometazoline drops). Some had also taken antibiotics (e.g., ofloxacin) for diarrhoea in which the underlying cause maybe an amoebic infection.

More number of medicos was concerned about the quality of medicines they took, and also $86 \%$ of them were aware of the probable side effects compared to only $65 \%$ Non-Medicos who knew the side effects. This percentage is higher when compared to a previous study [8] but similar to that obtained in another study where $82 \%$ Medicos were aware of the side-effects [11]. However, 8 participants reported side effects and adverse drug reactions after self-medication, severe being "fixed drug eruption" after taking levo-floxacin and "drowsiness" due to cetrizine. Few Non- Medicos complained of the same, one of them having itching and rashes after Self-medication.
This is a small account of the fact that improper self-medication can cause adverse effects and morbidities. And students need to be made better aware about this aspect.

Out of the 68 Medical students who selfmedicated- $29 \%$ of them find the practice unacceptable, $13 \%$ of them didn't support the practice- and still they practiced it. Out of 48 Non-Medical students who selfMedicated, only $6 \%$ found the practice unacceptable while only $4 \%$ did not support the practice. This shows that though, the Medical students are better aware about the various aspects of Self-medication, still they practice it more than the Non- Medicos.

The main reason behind this can be the feeling of Self-confidence which Medicos get after Self medicating, as it was reported by $10 \%$ of the Medicos as its major advantage. Other advantages were useful for mild illness, easy availability and time saving. $8 \%$ of them felt it had no disadvantages and $10 \%$ of the Non- Medicos didn't know any advantage. But such believes need to be discouraged as it is well known that many - symptoms can be safely and effectively treated by Self-medication, if anyone approaches a doctor for every minor ailment it would unnecessarily increase the workload on the already overburdened health services particularly in the government sector [1]. One of the advantages stated by a Non-Medical participant is that, "If you are a Non-Medico, you can get ideas about common illnesses and treatment."

$1 \%$ Medicos and 3\% Non- Medicos are not aware about any disadvantage of Self-medication. $83 \%$ Medicos feel adverse drug reactions can be a major disadvantage compared to only $47 \%$ of Non- Medicos who feel so. This can be attributed to the fact that Medicos are aware about what an adverse drug reaction is. Most of them feel that wrong medication can be taken and lack of knowledge about it can cause detrimental effects. This also indicates that having learnt about the Pathology of various diseases and about drugs they are well aware about how using a wrong drug by Self-medication can lead to disease aggravation- as cited by $54 \%$ Medicos as its disadvantage. Drug Interaction was also cited as a disadvantage by few Medicos.

In this study, the observations in the two groups are almost comparable. Other reported studies on Self-medication among Medical students have compared various aspects like advantages, disadvantages of Self-medication, drugs used and diseases for which drugs are used, but no study has compared this awareness with the Non-medical students. Though, medical Students have fared significantly better in this study, even the Non-Medicos are aware about the various aspects maybe due to convenient sources of information e.g., internet. 
However, gaps do exist and is needed to be bridged by making them better aware regarding the rational use of medicines-safety, correct dosage and toxic effects.

\section{CONCLUSION}

Medical students self-medicated more that the Non-Medical students. The main reason behind this can be the fact that Medicos have a better knowledge about the various aspects of self-medication which reflects the influence of medical studies and training. However, self-medication is an important issue and we should only encourage "responsible" self-medication practices.

\section{REFERENCES}

1. Sontakke, S.D., Bajait, C.S., Pimpalkhute, S.A., Jaiswal, K.M., Jaiswal, S.R. (2011). Comparative study of evaluation of Self-medication practices in first and third year Medical students. Int. J. Biol. Med Res, 2(2), 561-564.

2. Banerjee, I., Sathian, B., Gupta, R.K. (2016). Selfmedication practice among preclinical university students in a medical school from the city of Pokhara, Nepal. Nepal Journal of Epidemiology, 6(2), 574-81.

3. Kumar, R., Goyal, A., Padhy, B.M., Gupta, Y.K. (2016). Self-medication practice and factors influencing it among medical and paramedical students in India: A two-period comparative crosssectional study. Journal of Natural Science, Biology, and Medicine, 7(2):143-148.

4. Klemenc-Ketis, Z., Hladnik, Z., Kersnik, J. (2010). Self-Medication among Healthcare and NonHealthcare Students at University of Ljubljana, Slovenia. Med Princ Pract,19, 395-401

5. Helal, R.M., Abou-ElWafa, H.S. (2017). SelfMedication in University Students from the City of Mansoura, Egypt. Journal of Environmental and Public Health, 9145193.

6. Badiger, S., Kundapur, R., Jain, A. (2012). Selfmedication patterns among medical students in South India. The Australasian Medical Journal, 5(4), 217-220.

7. Banerjee, I., Bhadury, T. (2012). Self-medication practice among undergraduate medical students in a tertiary care medical college. West Bengal $\mathrm{J}$ Postgrad Med, 58(2), 127-31.

8. Patil, S.B., S. H. V., B.V. P., Santoshkumar, J., Binjawadg,i A.S., Kanaki, A.R. (2014).SelfMedication Practice and Perceptions Among Undergraduate Medical Students: A CrossSectional Study. Journal of Clinical and Diagnostic Research, JCDR, 8(12), 20-23.

9. Quoted by Brian Strom. (2011). Director of the Centre for Clinical Epidemiology and Biostatistics at the Perelman School of Medicine at the University of Pennsylvania, from http://usatoday30.usatoday.com/LIFE/usaedition/Overthecounter-drugdangers--_ST_U.htm
10. Al-Hussaini, M., Mustafa, S., Ali, S. (2014). Selfmedication among undergraduate medical students in Kuwait with reference to the role of the pharmacist. Journal of Research in Pharmacy Practice, 3(1),23-27.

11. Kasulkar, A.A., Gupta, M. (2015). SelfMedication Practices among Medical Students of a Private Institute. Indian Journal of Pharmaceutical Sciences, 77(2), 178-182.

12. Hughes, C.M., McElnay, J.C., Fleming, G.F. (2001). Benefits and risks of self-medication. Drug Saf, 24, 1027-37.

13. World Self-Medication Industry: Responsible selfcare and self-medication. A worldwide review of consumer surveys, from http:// www.wsmi.org.

14. Aljinovic-Vucic, V., Trkulja, V., Lackovic, Z. (2005). Content of home pharmacies and selfmedication practices households of pharmacy and medical students in Zagreb, Croatia: findings in 2001 with a reference to 1977 . Croat Med J, 46, 74-80.

15. Walsh, K. (2014). Self-medication among medical students: What strategies could help? Journal of Research in Pharmacy Practice, 3(3), 108.

16. Klemenc-Ketis, Z., Hladnik, Z., Kersnik, J. (2011). A cross sectional study of sex differences in selfmedication practices among university students in Slovenia.Coll Antropol, 35(2),329-34

17. Burak, L.J., Damico. A. (2000). College students' use of widely advertised medications. J Am Coll Health, 49(3) 118-21.

18. James, H., Handu, S.S., Khalid, A.J., Khaja, A., Otoom, S., Sequeira, R.P. (2006). Evaluation of the knowledge, attitude and practice of Selfmedication among first-year Medical students. Med Princ Pract, 15, 270- 275.

19. Kayalvizhi, S., Senapathi, R. (2010). Evaluation of the perception, attitude and practice of selfmedication among business students in 3 select cities, South India. IJEIMS, 1(3), 40-44

20. Verma, R.K., Mohan, L., Pandey, M. (2010). Evaluation of self-medication among professional students in North India: proper statutory drug control must be implemented. Asian J Pharmaceutical Clin Res, 3(1), 60-64

21. Abay, S.M., Amelo, W. (2010). Assessment of self-medication practices among medical, pharmacy, and health science students in Gondar University, Ethiopia. J Young Pharm, 2(3), 306310

22. Gutema, G.B., Gadisa, D.A., Kidanemariam, Z.A., Berhe, D.F., Berhe, A.H. (2011). Self-Medication Practices among Health Sciences Students: The Case of Mekelle University J Appl. Pharmaceutical Sci, 01(10), 183-189

23. Fadare, J.O., Tamuno, I. (2011). Antibiotic selfmedication among university medical undergraduates in Northern Nigeria. J Public Health Epidemiol, 3(5), 217-220 
24. Ali, S.E., Ibrahim, M.I.M., Palaian, S. (2010). Medication storage and self-medication behaviour amongst female students in Malaysia. Pharm Pract, $8(4), 226-232$

25. James, H., Handu, S.S., Khaja, K.A., Sequeira, R.P. (2008). Influence of Medical training on Selfmedication by students. Int J Clin Pharmacol Ther, 46(1),23-29.

26. Smogavec, M., Softič, N., Kersnik, J., KlemencKetiš, Z. (2010). An overview of self-treatment and self-medication practices among Slovenian citizens. Slovenian Med J. 79, 757-763 27.
27. Ghaieth, M.F., Elhag, S.R.M., Hussien, M.E., Konozy, E.H.E. (2015). Antibiotics selfmedication among medical and nonmedical students at two prominent Universities in Benghazi City, Libya. Journal of Pharmacy \& Bioallied Sciences; 7(2):109-115.

28. World Health Organization: Report of the WHO Expert Committee on National Drug Policies. 1995.

http://www.who.int/medicines/library/dap/whodap-95-9/who- dap- 95.9.shtml. (last accessed on 09/3/2011) 